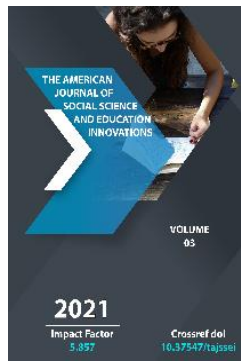

\title{
Psychological Characteristics Of Emotional Intelligence Formation In Small School Age
}

\author{
Xayitova Zilola Muhammadjanovna \\ 2nd Year Doctoral Student, Andijan State University, Uzbekistan
}

Journal Website:

http://usajournalshub.c

om/index,php/tajssei

Copyright: Original content from this work may be used under the terms of the creative commons attributes 4.0 licence.

\section{ABSTRACT}

The article describes the results of a study of the formation of emotional intelligence in older preschool children. The definition of emotional intelligence is given, a two-level structural model of this concept is presented, as well as the model and methods of development and formation of emotional intelligence in preschoolers. From the earliest stage of life, children have a lot of emotions. They show various feelings such as anger, fear, joy, pride, shame, etc. This whole system of feelings forms the emotional sphere of human life. Emotions give children information about their condition and that of the other person. Positive emotions make children feel safe and secure. On the contrary, negative emotions signal danger and displeasure.

\section{KEYWORDS}

Senior preschooler, emotions, emotional state, emotional intelligence, emotional orientation to another person, willingness to take care of another, the program for the formation of emotional intelligence.

\section{INTRODUCTION}

Emotions are of paramount importance for the upbringing of socially significant traits in a 
person: humanity, responsiveness, compassion; emotional intelligence is the basis of a person's social success.

The ability to understand emotions, feelings and experiences - your own and others', refers to the so-called soft skills that are important for people of any age. However, it is in early adolescence that emotional intelligence is the basis of the leading type of activity communication and its components (communication, interaction, perception), being an important age-related need. In this connection, it is important to search for and develop effective methods for the development of emotional intelligence, taking into account the age characteristics of younger adolescents and the structure of the studied phenomenon.

Emotional intelligence is formed during a person's life and is influenced by a number of facts:

- $\quad$ Cognitive abilities (speed and accuracy of processing emotional information);

- Ideas about emotions (as values, as an important source of information about oneself and about other people, etc.);

- $\quad$ Features of emotionality (emotional stability, emotional sensitivity, etc.).

In order for a child to be able to successfully adapt in society, he needs to learn to be able to control his feelings and emotions, to consciously influence them and to be able to recognize and acknowledge the feelings of other people, i.e. have a developed emotional intelligence. Due to the relevance of the problem, the goal of our research is theoretical and experimental study and development through psychogymnastics of emotional intelligence in primary schoolchildren.
The emergence of the term "emotional intelligence" was preceded by "a gradual change in views on the relationship between emotional and intellectual processes. We can find the study of the problem of emotionalcognitive interaction in the early works of ancient philosophers. They separated emotions and reason into separate spheres. The dominance of reason over emotions was also emphasized. Then, as psychological knowledge develops within the framework of philosophy, there is an intensification of empirical research in the field of thinking and emotion. Here the authors linked the mutual influence of emotions and intellect with human functioning in everyday life. This was followed by the stage of the differentiated study of emotions and intelligence, where the features of the interaction of emotions and intelligence were considered in the mainstream of the psychology of intelligence and separately within the framework of the psychology of emotions. In the psychology of emotions, an important, but still auxiliary, role of cognitive processes was recognized, and in the psychology of intelligence, emotional experiences were assigned a secondary role. Further, there is an increase in interest in the study of the peculiarities of the mutual influences of emotions and intellect "

The idea of the modern understanding of emotional intelligence "in the form in which this term exists now, grew out of the concept of" social intelligence ", the authors of which are E. Thorndike, J. Hilford, G. Eysenck. In the development of psychological science and its component - the psychology of intelligence, at a certain period of time, much attention began to be paid to information models of intelligence, and the affective component of thinking receded into the background. The 
concept of "social intelligence" was the link between the cognitive and affective sides of the cognition process. "

According to E. A. Alyabyeva, "it was emotional intelligence in its modern understanding that was the main thing for human survival in prehistoric times, since it manifests itself in the ability to adapt to the environment, live in peace and find a common language with fellow tribesmen and neighboring tribes"

The founder of psychoanalysis, Z. Freud, was also involved in the issue of emotions and control over them. D. Wexler made a significant contribution to the study of intelligence, who alized intelligence as "the aggregate ability of an individual to act purposefully, to think expediently and to effectively interact with the world around him."

It is believed that emotional intelligence is a much more important factor for a person's success than "normal" intelligence - IQ. A person with high emotional intelligence is proactive, will find a way out of any difficult situation, and will easily and constructively solve all problems. The owner of high emotional intelligence is pleasant in communication, tries to avoid conflict situations, is self-sufficient and independent, realistically evaluates his abilities. A high level of emotional intelligence corresponds to the highest level of development of a person's inner world. The motivation of the behavior of such a person is carried out not from the outside, but exclusively from the inside. Such a person is extremely difficult to manipulate, he feels a high level of psychological well-being and lives well in harmony with himself and the people around him.
The structure of emotional intelligence, proposed by J. Meyer, P. Salovey, D. Caruso, includes the following components: conscious regulation of emotions, understanding (comprehension) of emotions, assimilation of emotions in thinking, discrimination and expression of emotions.

D. Goleman, unlike P. Salovey and J. Mayer, believes that a person can develop and improve emotional intelligence throughout his life. The author argues that the structure of emotional intelligence has broader boundaries and includes the following components: selfawareness, self-control, social sensitivity, relationship management.

In modern psychological and pedagogical science, the study of the nature and components of emotional intelligence and the characteristics of its development in primary school age is in demand and relevant. The complexity and inconsistency of this direction of research is manifested in both theoretical and practical aspects. This is due to the fact that the concept of "emotional intelligence" first appears in foreign psychological science in the works of J. Meyer, D. Goleman, P. Salovey in the twentieth century and after it is used in domestic science. However, the studies of recent decades in the development of the concept itself have not brought clarity. In modern society, the concept of "emotional intelligence" is more a commercialized concept, a brand, than a scientific concept that requires detailed research. However, theoretical analysis allows us to put forward a different point of view on this understanding. The concept of "emotional intelligence" arises in the development of social intelligence, which, according to the works of E. Trondike, is a person's ability to 
understand other people, to act wisely in relation to others. The main function of emotional intelligence is to predict behavior, the most likely reactions of other people.

Modern concepts of "emotional intelligence are rather broad and vague. An analysis of the main research positions on the topic under discussion allows us to conclude that the current state of the issue of emotional intelligence in psychological science does not provide an opportunity for a unified interpretation of this construct. There is a need for systematization, generalization of the available data, as well as the formation of the scientific foundations of emotional intelligence. A theoretically substantiated definition of the very concept of emotional intelligence, clarification of the structure of this phenomenon is required. This will allow defining scientifically based methods for diagnosing emotional intelligence and its practical significance."

The ability to build information, to form a conclusion with a minimum of information is a function of intelligence, while if the information belongs to the emotional sphere, then emotional intelligence can be singled out separately as an independent psychological phenomenon. In his writings, D. Goleman emphasized that emotional intelligence directly affects a person's success in life.

So, emotional intelligence is the ability to perceive and understand emotions manifested by a person, as well as to manage their emotions on the basis of intellectual processes; the ability to determine their emotional states and emotions of other people, for the successful use of the information received in the implementation of their own goals. Thus, it can be emphasized that emotional intelligence is a systemic integrative education.

The following components are distinguished in emotional intelligence: perception, understanding, identification of emotions, behavior in accordance with emotional experiences. The development of emotional intelligence allows a person to be aware of their own emotions, to manage them. And also recognize the emotional manifestations of other people. So, the ability to understand emotions allows you to establish the fact of the existence of the experience of emotional states. Emotion identification allows you to determine what emotion is experienced by a person and choose the appropriate verbal expression for this. Understanding emotions involves understanding the reasons that caused a given emotion and what consequences this emotion will lead to. The ability to manage emotional states implies a person's control of the intensity of their manifestation, the ability to muffle their excessively strong manifestations, control of their external manifestation, voluntary manifestation of these emotions.

The relevance of the development of emotional intelligence at primary school age is due to the psychological and pedagogical characteristics of children at this stage of ontogenesis. During this period, the emotional sphere of primary schoolchildren is actively developing, self-awareness, opportunities for reflection, the ability to take a side view of the situation, and also take into account the feelings and needs of another person are improving. In elementary school, selfregulation of behavior gradually develops in the process of daily performance of school duties, compliance with the norms of behavior 
in school, compliance with the requirements from the teacher to the students, and later from the team.

One of the leading directions in the organization of children's educational institutions is the upbringing of an orientation towards another person, since only through another person a child experiences his experience of social interaction and receives knowledge to build relationships with the world around him. One of the main reasons for ineffective cooperation and communication in adult life is the lack of skills to build relationships that are acquired by a child already in preschool age.

In early school age, emotional development outstrips intellectual development. Therefore, one of the most pressing issues of preschool education is the problem of moral ideas of the individual and the development of humane feelings. Insufficient development of this area of the psyche, as studies show.

The problem of the development of emotional intelligence is most relevant in preschool age. On the one hand, childhood is a period of formation of mental functions, personality formations and qualitative changes in the development of psychological processes. Probably the most important difference between IQ and Emotional Development is that the latter is least associated with genetic factors, which gives more importance to the process of early childhood education and socialization at this age. On the other hand, programs for the development of emotional intelligence for preschoolers should be adequate for their age and leading activity. However, in our opinion, the existing programs for the development of emotional intelligence do not have a holistic approach and freedom of emotional expression, and are aimed only at certain characteristics of emotional intelligence.

In this regard, contradictions arise between:

- The importance of the problem of emotional intelligence and its insufficient theoretical development as the most important sociopsychological mechanism of socialization of a child, taking into account the specifics of primary school age in order to form a psychologically mature personality in the future;

- The significance of the level of development of the emotional intelligence of older preschoolers and the lack of practical realization in the individual-group work of educators and teachers in the process of education and training within the framework of school institutions;

- $\quad$ Available psychological and diagnostic techniques, practical material for working with older preschoolers and insufficient development of psychological and pedagogical conditions for optimizing the process of forming the emotional intelligence of younger students.

L.S.Vygotsky once pointed out the joint work of the intellectual and emotional-volitional sphere of a person's personality in order to ensure the effective functioning and adaptation of a person in the environment. In psychology, the principle of the unity of affect and intellect is best expressed by the concept of emotional intelligence. 
According to I. N. Andreyeva, the skills of emotional intelligence are based on the conditions of family communication, on the emotional experience formed in the process of emotional contact with parents. Thus, the author comes to the conclusion that a favorable atmosphere in the family is a condition for the development of emotional intelligence in primary schoolchildren.

The development of human emotional intelligence is becoming one of the urgent problems of modern psychology. There are many socio-economic factors that have a destructive effect on the development of the emotional sphere, for example, an acceleration of the pace of life, an increase in emotional stress, an increase in the level of anxiety, etc.

Scientists have proven the connection between human emotions and his thinking. So, L.S. Vygotsky noted that "thinking arises only on an instinctive and emotional basis and is directed by the forces of the latter."

\section{REFERENCES}

1. Akimova M.K., Kozlova V.T. Psychological correction of the mental development of schoolchildren: a textbook. - 2nd ed., Stereotyped. - M .: Academy, 2002 .-- 160 p.

2. Belobrykina O.A. The influence of the social environment on the development of selfesteem // Questions of psychology. - 2001. No. 4. - S. 31-38.

3. Bozovic L.I. Personality and its formation in childhood. - SPb .: Peter, 2008 .- 400 p. (Masters of Psychology).

4. Zakharova A.V., Andrushchenko T.Yu. Research of self-esteem of younger schoolchildren in educational activity // Questions of psychology. - 1980. - No. 4. - P. 90-99.

5. Mental development of primary schoolchildren / Ed. V.V. Davydov. - M .: Pedagogy, 1990 - $160 \mathrm{p}$. 